FIRST-YEAR TECHNICIAN MATHEMATICS 


\section{FIRST-YEAR TECHNICIAN MATHEMATICS}

for Electrical, Electronics and Telecommunications Students

RHYS LEWIS

B.Sc. Tech., C.Eng., M.I.E.E.

Senior Lecturer, Openshaw Technical College, Manchester 
(C) Rhys Lewis 1974

\section{Reprint of the original edition 1974}

All rights reserved. No part of this publication may be reproduced or transmitted, in any form or by any means, without permission

First published 1974 by

THE MACMILLAN PRESS LTD

London and Basingstoke

Associated companies in New York Dublin

Melbourne Johannesburg and Madras

SBN 333174119

Type-setting by The Whitefriars Press Ltd

The paperback edition of this book is sold subject to the condition that it shall not, by way of trade or otherwise, be lent, re-sold, hired out, or otherwise circulated without the publisher's prior consent in any form of binding or cover other than that in which it is published and without a similar condition including this condition being imposed on the subsequent purchaser. 


\section{Contents}

Preface

1 Arithmetic 1

Basic Operations in Arithmetic $\quad 1$

Order of operation - the equality symbol

Simplification of fractions

Calculations with Fractions $\quad 5$

Multiplication - division - addition and subtraction
Orithmetical Processes - Raising to a power

Raising to the power unity and zero - multiple powers - use of

factors - raising fractions to a power - fractional powers - negative powers and reciprocals

Systems of Numbers

Number of digits - numbers larger than the base - order of digits - binary and decimal fractions

Manipulation of Numbers Containing a Decimal-Point

Addition - subtraction - multiplication - division - approxi-

mations - standard form - powers of ten - conversion of decimal fractions to proper fractions - percentages

2 Aids to Calculation $\quad 49$

Logarithms

Logarithms of numbers less than 1 - roots and powers

Roots and Reciprocals from Tables

The Slide Rule

Using the slide rule - multiplication - division 
Basic Considerations

Addition - subtraction - multiplication - division

Algebraic Fractions

Powers

Meaning of powers

4 Formulae and Equations

Transposition

Evaluation of Formulae

90

Simple Linear Equations

92

Simultaneous Linear Equations

97

Ratio and Proportion

102

5 Graphs

The Straight-line Graph

The gradient - the intercept - general equation of the straight-line graph - deducing the equation of a straight-line graph

Graphical Solution of Simultaneous Equations

6 Geometry

Definitions

Angles associated with parallel lines

Properties of Triangles

Sum of interior angles - exterior angles - similar and congruent

triangles - isosceles and equilateral triangles - right-angled triangles

Properties of Quadrangles and Other Polygons

Properties of Circles

Areas

Area of triangles - area of a trapezium - area of a circle

Volumes

7 Trigonometry

Functions of Angles

The sine function - the cosine function - the tangent function trigonometric functions of $0^{\circ}, 30^{\circ}, 45^{\circ}, 60^{\circ}$, and $90^{\circ}$

Graphs of $\operatorname{Sin} \theta$ and $\operatorname{Cos} \theta$ 
Contents

Test Papers

Answers to Exercises

Answers to Test Papers 


\section{Preface}

This book is the first in a series of three covering the mathematics syllabuses of courses leading to Electrical and Electronic Technician and ultimately Technician Engineer status. At the present time these courses include the City \& Guilds of London Institute courses $280,281,285,270$ and 272 and the titles of the books breaking the syllabuses into four years (the third-year text to include mathematical applications) stem from the organisation of these courses. With the advent of the Technician Education Council and subsequent reorganisation of courses it may be found that the breakdown by year will change. However it is anticipated that the total content of all three books will more than adequately cover the total syllabus content of all electrical and electronic technician courses both present and proposed. All three books contain a large number of examples both worked and otherwise and finish with a number of typical examination papers covering the content of each volume.

The assistance and advice of Mr Noel Morris, the series editor, is gratefully acknowledged. In addition the author would particularly like to thank Mrs L.J.E. Jones for typing the manuscript. 